Abstract

\title{
Exploring Diversification Drivers in Golden Orbweavers ${ }^{\dagger}$
}

\author{
Eva Turk ${ }^{1}$, Simona Kralj-Fišer ${ }^{1}$ and Matjaž Kuntner ${ }^{1,2}$
}

1 Institute of Biology, ZRC SAZU, Ljubljana, Slovenia; eva.turk@zrc-sazu.si(E.T.); simonakf@zrc-sazu.si (S.K.-F.); Matjaz.Kuntner@nib.si (M.K.)

2 National Institute of Biology, Ljubljana, Slovenia

* Correspondence:

† Presented at the 1st International Electronic Conference on Biological Diversity, Ecology and Evolution, 15-31 March 2021; Available online: https://bdee2021.sciforum.net/.

Published: date

\begin{abstract}
Heterogeneity in species diversity is driven by the dynamics of speciation and extinction, potentially influenced by organismal and environmental factors. Here, we explore macroevolutionary trends on a phylogeny of golden orbweavers (spider family Nephilidae). Our initial inference detects heterogeneity in speciation and extinction, with accelerated extinction rates in the extremely sexually size dimorphic Nephila and accelerated speciation in Herennia, a lineage defined by highly derived, arboricolous webs, and pronounced island endemism. We evaluate potential drivers of this heterogeneity that relate to organisms and their environment. Primarily, we test two continuous organismal factors for correlation with diversification in nephilids: phenotypic extremeness (female and male body length, and sexual size dimorphism as their ratio) and dispersal propensity (through range sizes as a proxy). We predict a bell-shaped relationship between factor values and speciation, with intermediate phenotypes exhibiting highest diversification rates. Analyses using SSE-class models fail to support our two predictions, suggesting that phenotypic extremeness and dispersal propensity cannot explain patterns of nephilid diversification. Furthermore, two environmental factors (tropical versus subtropical and island versus continental species distribution) indicate only marginal support for higher speciation in the tropics. Although our results may be affected by methodological limitations imposed by a relatively small phylogeny, it seems that the tested organismal and environmental factors play little to no role in nephilid diversification. In the phylogeny of golden orbweavers, the recent hypothesis of universal diversification dynamics may be the simplest explanation of macroevolutionary patterns.
\end{abstract}

\section{Keywords:}

Publisher's Note: MDPI stays neutral with regard to jurisdictional claims in published maps and institutional affiliations.

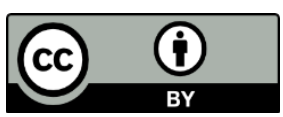

(C) 2021 by the authors. Licensee MDPI, Basel, Switzerland. This article is an open access article distributed under the terms and conditions of the Creative Commons Attribution (CC BY) license (http://creativecommons.org/licenses/by/4.0/). 